\title{
Patterns of Paediatric Maxillofacial Fractures: A Twelve-Year Retrospective Study
}

\author{
Musaev Shamshodbek Shuxratovich ${ }^{1}$, Shomurodov Kahramon Erkinovich ${ }^{2}$,

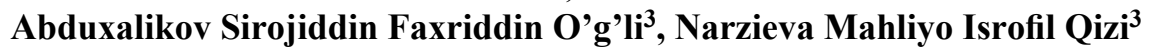 \\ ${ }^{1}$ Phd Student, Department of Paediatric Maxillofacial Surgery, Tashkent State Dental Institute, Uzbekistan, \\ ${ }^{2}$ Dsc, Docent \& Head, of Department of Maxillofacial Surgery, Tashkent State Dental Institute, Uzbekistan, \\ ${ }^{3}$ Postgraduate, Department of Paediatric Maxillofacial Surgery, Tashkent State Dental Institute, Uzbekistan
}

\begin{abstract}
In this study was to analyse the patterns of maxillofacial fractures in children under 18 years of age admitted at paediatric maxillofacial surgery department in Tashkent state dental institute, Uzbekistan in a period of 12 years between January 2007 and December 2018. Out of 757 children with maxillofacial bone fractures, the majority were aged between $6-18$ years $(78,6 \%, n=595)$. The mean $( \pm S D)$ age was $9.3 \pm 0.5$ years and male to female ratio was $6.2: 1$. Falls was the most frequent mode of injury $(46,9 \%, n=355)$. The mandible was most commonly involved $(67.2 \%, \mathrm{n}=509)$ of the cases. The incidence of paediatrics maxillofacial fractures in Uzbekistan region was high. The 6-18-year olds and boys were most commonly involved in maxillofacial paediatrics trauma. Mandibular fractures were the most common type of fracture. Safety programs should be instituted in Uzbekistan region to increase public awareness and to decrease morbidity resulting from paediatrics maxillofacial trauma.
\end{abstract}

Keywords: Paediatric, Maxillofacial area, Trauma, Mandibular fractures.

\section{Introduction}

Head injuries of children are common, comprising more than half of all injuries sustained. The mortality and morbidity rates associated with traumatic head injury in children are high and the majority of deaths due to trauma in children are caused by brain injury ${ }^{1,2}$. Trauma is a leading cause of injury and death among the paediatric population. There is a pattern of facial fractures by age that is influenced by trends in the mechanism of injury and facial development. Cranial and central facial injuries are more common in toddlers and infants and mandibular fractures are more common

\section{Corresponding Author:}

Musaev Shamshodbek Shuxratovich

PhD Student (Department of Paediatric Maxillofacial Surgery), Tashkent State Dental Institute, 100077,

Tashkent, Uzbekistan

Contact: +998934700753;

e-mail:shamshodbek@inbox.ru in adolescents and beyond. A large proportion of facial fractures were caused by fall ${ }^{4,5}$. The exponential rise in the incidence of facial fractures associated with skull fractures in children reflect the growth and development of the face to downward and forward direction that make it more susceptible to trauma. Paediatric facial fractures account for $25 \%$ of all maxillofacial injuries ${ }^{1,3,6,7,8,11}$.

The most prevalent cause of facial fractures in paediatric patients are accidental falls (58.2\%) including falling on the floor when playing, falling from bed and stairs, and falling from height, followed by violence $(12.7 \%)$, bicycle $(10 \%)$, and motor vehicle accidents $(8.2 \%)$. Sports injuries represented only $7.3 \%$ and others $3.6 \%[2,5]$ Nasal fractures were the most common $(69.1 \%)$ and condyle was the most common site of mandibular fractures $(63.2 \%)$. The mandible was the most common bone to fracture $(65 \%)$ and the body of the mandible was the commonest site to be involved by fracture $(27 \%)$. Only $10 \%$ of cases involved both jaws ${ }^{12}$. The zygomatic bone appeared to be the most common bone involved in mid-face fractures $(45 \%)^{6}$. 
The minimally displaced mandibular fracture is usually managed by a short course of maxillamandibular fixation (MMF) usually 21 days using elastics ${ }^{6,9,10}$. The use of open reduction and rigid internal fixation without maxillomandibular fixation also has obvious advantages for the management of children with multiple injuries. The aim of this study was to analyze the patterns of facial fractures in children up to eighteen years of age admitted at paediatric maxillofacial surgery department in Tashkent state dental institute, Tashkent city, Uzbekistan retrospectively in the last twelve years (2007-2018).

\section{Material and Method}

All paediatric patients under 18 years admitted at the department of paediatric maxillofacial surgery of Tashkent state dental institute diagnosed with maxillofacial fracture were included in this study. The study was a twelve years retrospective study from January 2007 - December 2018. The data collected from the patients records included, age, gender, etiology, type of injuries.

Inclusion Criteria: All paediatric patients under 18 years admitted to paediatric maxillofacial surgery department with maxillofacial bone fractures.

\section{Exclusion Criteria:}

1. Fractures involving the skull vault or frontal bone were not included in the study because children with cranial bone fracture are usually referred and managed by neurosurgery according to the hospital policy.

2. Soft tissue injuries were not included in the study as they are mainly treated at emergency departments without recording.

3. Patients with dental trauma also were not included in the study as they were either managed at emergency departments without recording or refereed to pedodontist at dental center.

The study was conducted at the department of paediatric maxillofacial surgery at Tashkent state dental institute following the approval from research centre of Tashkent state dental institute and hospital ethical committee. Statistical analysis was performed using Statistical Package for Social Sciences (IBM SPSS), Version 25.0 for Windows 10.

\section{Results}

The incidence of paediatric maxillofacial fractures in relation to age group: out of 757 children with maxillofacial bone fractures, $78.6 \%(\mathrm{n}=595)$ were $6-18$ years (school age) old and $21.4 \%(n=162)$ were under 5 years (pre-school) of age. It can be seen that children in the 6-18 years age group were more commonly involved with a peak incidence at $<12$ years. The mean age was $9.3 \pm 0.5$ (SD) years, ranging from 2-18 years. Gender distribution showed that $86.1 \%(n=652)$ were males and $13.9 \%(\mathrm{n}=105)$ were females with a male to female ratio of $6.2: 1$.

Falls were the most frequent mode of injury ( $46.9 \%$, $\mathrm{n}=355)$, followed by sport $(26.8 \%, \mathrm{n}=203)$, bicycle accident $(21.1 \%, \mathrm{n}=160)$, and RTAs $(5.2 \%, \mathrm{n}=39)$. The mandible was most commonly involved $(67.2 \%$, $\mathrm{n}=509)$, followed by nasal $14.9 \%(\mathrm{n}=113)$, dentoalveolar fractures $(8.1 \%, \mathrm{n}=61)$, zygoma $(5.9 \%, \mathrm{n}=45)$, maxilla $(3.8 \%, \mathrm{n}=29)$ fractures, respectively.

Cross-tabulation showed 6-18 years age group was more likely to have facial fractures in all sites. Association between gender and site of facial fracture by crosstabulation showed male were more likely to have facial fractures in all sites than female shows the association between site of paediatric facial fractures and mode of injury. All sites of fracture except dentoalveolar were more likely to be due to falls. Dentoalveolar fracture was more likely to be due to sport.

\section{Discussion and Conclusions}

The current study showed that males were more susceptible to facial trauma than females. More frequently young children sustain injuries from lowvelocity forces than older children who are more likely to be exposed to high velocity forces ${ }^{12}$. In the present study, falls were the most prevalent etiological factor of facial fractures. This is in agreement with the reports by Lee $(2009)^{5}$ who stated that falls are a major health hazard.

The mandible was the most common site $(67.2 \%)$ which is in agreement with the majority of studies which have reported the mandible as being the most common bone involved in paediatrics facial fractures ${ }^{13,14}$.

The twelve years incidence of paediatrics facial fractures in Uzbekistan region was higher in 6-18 
year olds and boys were more commonly involved in maxillofacial paediatrics trauma. The most common etiological factor was falls. Mandibular fractures were the leading type of fracture. This data serves as a warning to maxillofacial surgeons to provide the proper and early management to prevent farther facial asymmetry or occlusion disturbances. It is also recommended that researchers should conduct future studies analysing the post-operative deformity for the managed children in the same hospital.

\section{Conflict of Interest: None}

Ethical Clearance: Taken from the Ethical Committee from the Institute.

Source of Funding: Nil

\section{References:}

1. Arraj GP, Rossi-Fedele G, Dogramaci EJ. The association of overjet size and traumatic dental injuries- a systematic review and meta-analysis. Dent Traumatol 2019;35(4-5):217-32

2. da Costa Nardis A, Costa SAP, da Silva RA, Kaba SCP: Patterns of paediatric facial fractures in a hospital of São Paulo, Brazil: A retrospective study of 3 years. Journal of Cranio-Maxillofacial Surgery2013, 41(3):226-229.

3. Flores MT, Onetto JE. How does orofacial trauma in children affect the developing dentition? Longterm treatment and associated complications. Dent Traumatol 2019;35(6):312-23.

4. Kim SH, Lee SH, Cho PD. Analysis of 809 facial bone fractures in a pediatric and adolescent population. Arch Plast Surg 2012;39:606-11.

5. Lee KH: Epidemiology of facial fractures secondary to accidental falls. Asian Journal of Oral and Maxillofacial Surgery 2009, 21(1-2):33-37.

6. Mong TK, Mustafa WMW, Sockafngam G: Paediatric Facial Fractures: One-year Survey of 23 Government Hospitals in Malaysia. Asian Journal of Oral and Maxillofacial Surgery 2007,19(1):3033.
7. Shomurodov KE, Kuryazova ZK, Isomov MM, Mukimov II, Fayziyev BR. Improvement of surgical treatment of fractures of the inferior orbit wall. J Stomatologiya2017;2:78-80. Avialable from URL: https://www.elibrary.ru/item.asp?id=37073416

8. Shomurodov KE, Musaev SS, Olimjonov KJ. Influence of immobilization method on periodontal tissues during treatment fractures of the lower jaw in children. Journal of oral medicine and craniofacial research 2020;1(1):8-11. http://dx.doi. org/10.26739/2181-0966-2020-1-1

9. Yakubov RK, Mukhamedov IM, Khodzhimetov AA and etc. Comprehensive diagnosis and treatment of fractures of the lower jaws in children: Method. recommendations for practitioners dentists general. Pract., Maxillofacial surgeons, masters. Tashkent, 2009. $15 \mathrm{p}$.

10. Yakubov RK, Sharipova AU, Fayziyev BR, Yakubova NA, Yakubov RR Substantiation of pharmacological correction in the complex treatment of mandibular fractures and their early complications in children. Stomatologiya 2008,34:49-51.

11. Zhou, Wei, et al. Analysis of pediatric maxillofacial trauma in North China: Epidemiology, pattern, and management. Injury 2020;51(7):1561-1567. https://doi.org/10.1016/j.injury.2020.04.053

12. Zimmermann C, Troulis M, Kaban L: Pediatric facial fractures: recent advances in prevention, diagnosis and management. International journal of oral and maxillofacial surgery 2005,34(8):823-833 .

13. Ferreira PC, Amarante JM, Silva PN, Rodrigues JM, Choupina MP, Silva ÁC, Barbosa RF, Cardoso MA, Reis JC: Retrospective study of 1251 maxillofacial fractures in children and adolescents. Plastic and reconstructive surgery 2005,115(6):1500-1508.

14. Scariot R, Oliveira IAd, Passeri LA, Rebellato NLB, Müller PR: Maxillofacial injuries in a group of Brazilian subjects under 18 years of age. Journal of applied oral science 2009,17(3):195-198. 